Better Preparing Sports Psychologists for the Demands of Applied Practice: The Emotional Labor Training Gap

Dr Rebecca F. Hings

University of Portsmouth

Portsmouth Business School, Richmond Building, Portland Street, Portsmouth, UK

PO1 3DE

$\mathrm{T}:+44(0) 2392844094$

E: rebecca.hings@port.ac.uk
Brunel University London

Division of Sport, Health and Exercise Sciences, Heinz Wolff Building, Kingston Lane, Uxbridge, UK,

UB8 $3 \mathrm{PH}$

$\mathrm{T}:+44(0) 1895268175$

E: rebecca.hings@brunel.ac.uk

Dr Christopher R. D. Wagstaff

University of Portsmouth

Department of Sport and Exercise Science, Spinnaker Building, Cambridge Road,

Portsmouth, UK,

PO1 2ER

$\mathrm{T}:+44(0) 2392845120$

E: chris.wagstaff@port.ac.uk

Dr Valerie Anderson

University of Portsmouth

Portsmouth Business School,

Richmond Building, Portland Street,

Portsmouth, UK,

PO1 3DE

$\mathrm{T}:+44(0) 2392844029$

E: valerie.anderson@port.ac.uk

Dr Sarah Gilmore

University of Exeter

Exeter Business School,

Rennes Drive,

Exeter, UK,

EX4 4PU

T: +44 (0)1392726459

E: s.gilmore2@exeter.ac.uk

Professor Richard C. Thelwell

University of Portsmouth

Department of Sport and Exercise Science,

Spinnaker Building, Cambridge Road,

Portsmouth, UK,

PO1 2ER

$\mathrm{T}:+44(0) 2392845164$

E: richard.thelwell@port.ac.uk 


\section{Better Preparing Sports Psychologists for the Demands of Applied Practice: The Emotional Labor Training Gap}

This research received no specific grant from any funding agency in the public, commercial, or not-for-profit sectors. This research has not been published or submitted simultaneously for publication elsewhere.

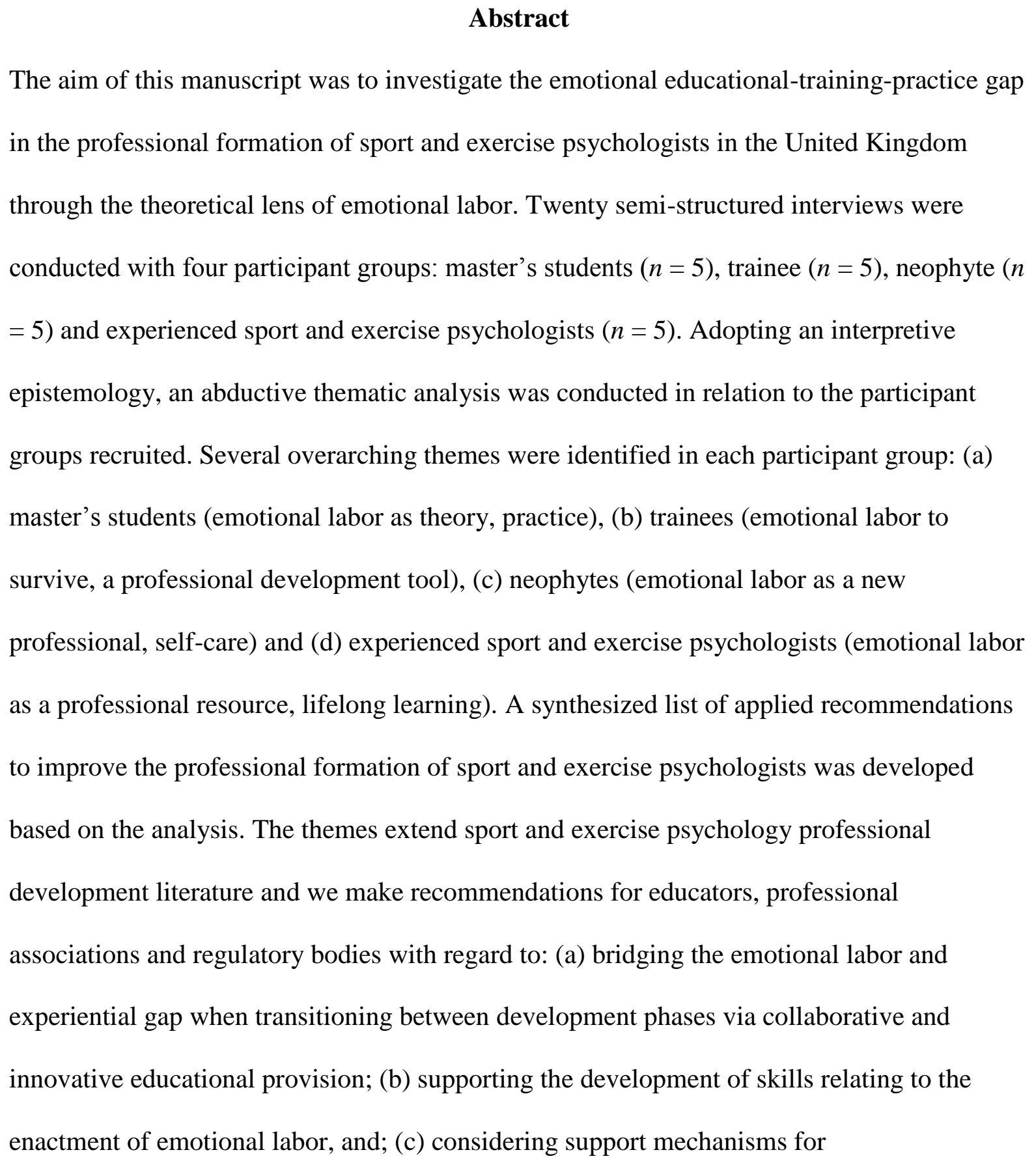

Abstract

The aim of this manuscript was to investigate the emotional educational-training-practice gap in the professional formation of sport and exercise psychologists in the United Kingdom through the theoretical lens of emotional labor. Twenty semi-structured interviews were conducted with four participant groups: master's students $(n=5)$, trainee $(n=5)$, neophyte $(n$ $=5$ ) and experienced sport and exercise psychologists $(n=5)$. Adopting an interpretive epistemology, an abductive thematic analysis was conducted in relation to the participant groups recruited. Several overarching themes were identified in each participant group: (a) master's students (emotional labor as theory, practice), (b) trainees (emotional labor to survive, a professional development tool), (c) neophytes (emotional labor as a new professional, self-care) and (d) experienced sport and exercise psychologists (emotional labor as a professional resource, lifelong learning). A synthesized list of applied recommendations to improve the professional formation of sport and exercise psychologists was developed based on the analysis. The themes extend sport and exercise psychology professional development literature and we make recommendations for educators, professional associations and regulatory bodies with regard to: (a) bridging the emotional labor and experiential gap when transitioning between development phases via collaborative and innovative educational provision; (b) supporting the development of skills relating to the enactment of emotional labor, and; (c) considering support mechanisms for 
student/trainee/neophyte safeguarding and welfare issues as a result of the emotion-laden transactions in professional practice. The implications for future pedagogy, andragogy and research are discussed.

Keywords: emotion regulation, professional practice, education, training

\section{Lay Summary}

Sports psychologists need to manage their emotions when working with athletes and coaches, but this is not often taught during education or training. This study aimed to understand whether sports psychologists were aware of or prepared to manage their emotions, and identify activities that could develop education and training courses.

\section{Better Preparing Sports Psychologists for the Demands of Applied Practice: The Emotional Labor Training Gap}

The incremental adoption of sport and exercise psychology services in elite sport has demanded a versatile skill set of service-delivery competencies to effectively navigate professional and personal challenges associated with high performance arenas. To successfully enact such competencies and respond to demanding contexts, recent research has demonstrated the importance of emotional labor (i.e., managing emotions and emotional expressions as part of the work role; Grandey \& Melloy, 2017), in the professional practice of sports psychologists (Hings, Wagstaff, Thelwell, Gilmore, \& Anderson, 2018). For example, the need to wear a "professional mask" to display desired and appropriate emotions when dealing with problematic athletes, despite an incongruence with felt emotions, has been reported (Hings, Wagstaff, Anderson, Gilmore, \& Thelwell, 2018). Despite the necessity of emotional labor in professional practice, it is unclear whether such skills are explicitly promoted throughout the professional formation of sport and exercise psychologists (SEPs). Nevertheless, a "practitioner skills gap" has been highlighted with regards to the application of knowledge and related technical skills associated with service delivery in prospective 
SEPs (Harwood, 2016, p. 243), but has yet to be evaluated through the theoretical lens of emotional labor. Indeed, Poczwardowski (2017) characterized the "consultant-as-performer" (p. 5) and the need for practitioners to adequately perform knowledge, skills and abilities when working with athletes regardless of personal or contextual demands. Thus, the purpose of this paper was to examine the emotional labor educational-training-practice gap in the professional formation of SEPs. A set of recommendations to improve educational and training provision was synthesized from the sentiments of those engaged in sport and exercise psychology.

\section{Professional Formation}

In the United Kingdom, the British Psychological Society (BPS) education and training pathway for prospective sports psychologists comprises three stages, (1) undergraduate degree or conversion course to achieve Graduate Basis for Chartered Membership (GBC), (2) Society accredited Master's in Sport and Exercise Psychology (Stage 1), and (3) Society Qualification in Sport and Exercise Psychology (Stage 2). Once qualified, practitioners are eligible to register as a Chartered Psychologist and acquire "Sport and Exercise Psychologist" status, a legally protected term under the Health Care and Professions Council (HCPC, 2018). Further, the BPS endorse a Continued Professional Development (CPD) scheme aimed at qualified SEPs to train specific skills required in the field. Although universities that offer BPS accredited courses often provide contemporary theoretical perspectives on service delivery to master's students within the confines of a classroom, it is only at "Stage 2 " that trainees are expected to engage in supervised practical consulting opportunities. Nevertheless, the BPS program has been critiqued by practitioners about how to deliver theoretical content at "Stage 1" ethically to facilitate practice preparedness (e.g., Harwood, 2016). 
Drawing from counselor-development literature, Tod (2007) argued that frameworks in neighboring psychology disciplines might positively contribute to the professional formation of SEPs. For example, Skovholt and Rønnestad (2011) developed a six-phase framework for therapist/counselor development that detailed the skills required at each phase for professional practice. For instance, interpersonal skills such as verbal (e.g., intonation), and non-verbal communication (e.g., appropriate facial expressions; Hings et al., 2018), and active listening (Fletcher \& Maher, 2013) encapsulate the social and performative aspects of practice. In accordance with the model's principles, previous findings have indicated the need for applied content throughout professional development to adequately train skills to achieve professional competencies that reflect "real world" practice. For example, educational demands for sports psychology master's students (e.g., social interactions inside and outside the classroom; Tod, Marchant, \& Andersen, 2007), neophytes (e.g., purposeful changes in approach to service delivery; Tod \& Bond, 2010), and experienced SEPs (e.g., professional and lifelong learning; Fletcher \& Maher, 2013) have been highlighted. Indeed, findings by McEwan and Tod (2013) comparing counselling, clinical, and sports psychologists' experiences of enhancing service-delivery competence confirm the importance of reflective learning, supervision, and work-based learning when practicing. While previous research has highlighted the need for practical activities to shape professional competencies, it remains unclear from an emotional labor perspective whether the specific interpersonal and expressive skills needed to succeed in high performance sport environments are adequately conveyed throughout the professional development of SEPs.

\section{Emotional Labor in Sports Psychology}

Various reflective (e.g., Tonn \& Harmison, 2004) and autoethnographical accounts (e.g., Lindsay, Breckon, Thomas, \& Maynard, 2007) have outlined the emotional intricacies related to developing appropriate yet flourishing working alliances, exploration of felt and 
concealed emotions, and taking on the role as "counsellor" when interacting with athletes, coaches, and other support staff. Despite these narratives, it is not yet understood how preparation for the enactment, or emotional "performance", of student, trainee, neophyte and experienced SEPs is addressed or developed within educational and professional formation processes. To meet performance expectations in elite sport requires frequent and variable emotional transactions between athletes and multi-disciplinary sports science and medicine teams (Hings et al., 2018). Specifically, Hings and colleagues (2018) demonstrated the necessity of sports psychologists to engage in emotional labor (e.g., surface acting in threatening situations) to successfully navigate everyday practice routines. Grandey and Gabriel (2015) conceptualized emotional labor as having three separate components, (a) emotional display requirements, (b) emotion regulation, and (c) emotion performance. Each facet of emotional labor requires a combination of socio-emotional skills and abilities to be applied effectively in professional situations to achieve desired end goals. For example, abilities such as emotional intelligence and situational awareness are crucial to interpreting organizational emotional display requirements (Wagstaff, Fletcher, \& Hanton, 2012). Further, physical skills such as adjusting verbal tone, non-verbal communication, and proximity to the client (i.e., emotion performance) are crucial to defusing professional challenges (Hings et al., 2018). Therefore, there is a need to align professional codes of conduct and education/training requirements with practice demands.

\section{The Present Study}

Tod and colleagues (2007) demonstrated the influence of theoretical perspectives on sports psychology service delivery, including an array of professional competencies required when consulting with athletes. Further, Woolway and Harwood (2018) provided a critical review of athletes' preferred sports psychology consultant characteristics and highlighted the importance of interpersonal skills such as the act of caring, being approachable and respectful 
towards athletes when building positive working relationships. Despite the potentially positive (e.g., increased sense of self and identity in the work role; Humphrey, Ashforth, \& Diefendorff, 2015) and negative (e.g., burnout; Grandey, Rupp, \& Brice, 2015, see also Larner, Wagstaff, Thelwell, \& Corbett, 2017) consequences of emotional labor, investigations into the pedagogical content delivered in relation to this phenomenon has been scarce. Given the necessity and complexities (i.e., physical and emotional skills, abilities, and awareness) required to enact emotional labor as a sports psychologist (Hings et al., 2018), it could be argued that a combination of theoretical and practical content that are representative of the interpersonal skills required to thrive as a sports psychologist, should be covered in the BPS education and training pathway. Hence, there is a need to investigate the level of preparedness for "real world" practice demands, whether professional competencies related to emotional labor are facilitated adequately, and the key skills deficits between the developmental phases in the sport and exercise psychology professional formation process (Harwood, 2016). To this end, we aimed to investigate the emotional labor educationtraining-practice gap in sport and exercise psychology using a qualitative semi-structured interview design. The following research questions guided the study: (1) To what extent are participants aware of the emotional demands, and practical skills required to enact the daily practice of a practitioner psychologist? (2) To what extent are participants prepared to enact emotional labor at each stage of development? (3) To what extent could current education and training provision be improved to sufficiently reflect the emotional labor of practitioner psychologists?

\section{Method}

\section{Design and Epistemological Approach}

The design of this study was informed by ontological relativism (i.e., the existence of multiple, contextual and subjective realities is assumed), and epistemological interpretivism 
(i.e., knowledge is constructed based upon participants' understanding of reality; Smith \& Sparkes, 2016). Specifically, a qualitative semi-structured interview design was employed to address the research questions. This method allowed for the adequate and flexible collection of data relating to the thoughts, feelings, and experiences of participants' educational development and reflections on the quality of their professional formation.

\section{Participants}

Prior to data collection, institutional ethical approval was granted and participant informed consent was obtained. Four separate population groups (see Figure 1) were recruited via a combination of convenience and purposive snowball sampling. The sampling criteria included those who were engaged in various stages of the sport and exercise psychology professional formation process in the United Kingdom (for inclusion and exclusion criteria, see Table 1). Thus, 20 participants were recruited from following populations groups, (1) master's level sport and exercise psychology students (Stage $1 ; n=$ 5), (2) trainee SEPs (Stage 2; $n=5)$, (3) neophyte SEPs $(n=5)$ and (4) experienced SEPs ( $n$ $=5$; mean experience 14.2 years). Participants in each group represented a range of institutions, locations, and sports. For anonymized demographic information, see Table 2.

\section{Data Collection}

Interviewees were recruited through initial email contact. The email included a participant information sheet detailing their ethical rights and what their involvement in the study would include, and an informed consent form. Those who indicated an interest were contacted to arrange an interview. All participants provided informed consent prior to the interview. The interviews lasted on average for 58 minutes and were conducted by the first author either face-to-face, online using Skype video calls, or over the telephone. Guidance on how to conduct interviews via multiple mediums was followed to ensure sufficient depth of 
data collection (Hanna, 2012; Sparkes \& Smith, 2014). All interviews were audio recorded via Dictaphone and handwritten notes were made concurrently.

Interview guide. A separate semi-structured interview guide was developed for each of the four population groups. Whereas topics of conversation were similar across the interview guides, the questions were worded in such a way that related to the level of experience participants gained in sport and exercise psychology education, training, and practice at the time of the interview. The participants were encouraged to reflect upon their current professional and/or educational experiences. There were three sections in the interview guide, (1) reflecting on acting as a SEP (e.g., skills and competencies required in practice), (2) sport and exercise psychology professional formation (e.g., undergraduate, postgraduate, and training experiences), and (3) recommendations to improve educational provision. Open-ended questions were used, and pertinent avenues of conversation deemed important to the research questions were probed.

\section{Data Analysis}

A thematic analysis was performed on the data implementing the guidance of Braun, Clarke and Weate (2016). This method was adopted to deliver a descriptive and interpretive conceptualization of the data (Vaismoradi, Turunen, \& Bondas, 2013), and provide insight into the participant's experiences with emotional phenomena in the context of their professional development. The analysis was abductive and was characterized by theoretical deduction (e.g., emotional labor and professional development literature, Grandey \& Gabriel, 2015; Skovholt \& Rønnestad, 2011), and inductive features, (e.g., innovative methods of teaching) which recursively influenced the development of themes. In line with Braun et al. (2016), the data were transcribed verbatim, and read and re-read by the first author to enable data familiarization. Then, the data were systematically and electronically coded using memos which aided the development of one codebook for each participant group. 
Throughout this process, the first two authors critically analyzed and reflected upon the data in relation to the research questions. Then, the codes were crafted and organized into themes for each participant group. Specifically, overarching themes representing the subthemes and the interconnectedness of each theme were developed. The themes were reviewed and refined by the research team by progressively altering, renaming and defining the themes. The final step of writing and presenting the data was integral to the creative analytical process.

Throughout the research process, a non-foundational approach to evaluating methodological rigor was adopted through the use of characterizing traits (Smith \& McGannon, 2017). The emotional and intellectual impact of the topic, and the coherence with which the research questions, method, and results create a meaningful picture, were taken into consideration when conducting the project (Burke, 2016). An audit trail of data collection and theoretical matters was maintained and the data represented aims for practitioner and academic resonance (i.e., facilitating naturalistic generalizations by presenting "thick descriptions and rich interpretations" of the research data that might relate to the readers own experiences; Smith, 2018, p. 142).

\section{Results}

The results are divided into four sections in relation to the participant groups: (a) Master's students (emotional labor as theory, practice), (b) Trainees (Supervised Practice; emotional labor to survive, a professional development tool), (c) Neophytes (emotional labor as a new professional, self-care), and (d) Experienced SEPs (emotional labor as a professional resource, lifelong learning). The overarching themes and sub themes are presented separately for the purposes of data organization, yet involve interrelated concepts associated to the research questions.

\section{Master's Students (Stage 1)}


Emotional labor as theory. Participants recollected specific implicit aspects of emotional labor in their studies (i.e., content related to lectures, seminars, coursework assignments), although emotional labor as a process was not explicitly taught, reflecting a gap in their knowledge.

Need for theoretical understanding. Participants placed emphasis on promoting holistic or humanistic support of athletes and understood the influence of philosophical approaches on service delivery. Despite students having a general understanding of the variety of emotional needs clients might have when developing a working alliance (Cropley, Hanton, Miles, \& Niven, 2010), participants reported a reliance on theoretical knowledge when describing their expectations of applied practice. For example, Gracie was uncertain of what to expect and highlighted the potential complexities athletes could present,

Depending on the approach that you might use, I would feel quite unprepared if I came across a situation which was not within my boundary of practice. The need to integrate your morals and personal views of the situation could be quite difficult as well as knowing what to do or how to respond in that situation.

Participants found it difficult to pinpoint whether emotional labor was communicated during their studies, and the topic was often implicitly conveyed within the coverage of theory or research methods within curricula as Abu explained, "We did one practical sports psychology course and the emotional demands of psychology was touched upon, but the focus was intake interviews" Abu added, "We did touch on emotions a little bit in the counselling module, when we covered topics like anxiety, but it was very brief. We haven't looked at emotion or emotional control explicitly as a wider topic for practitioners." Despite this, participants did not underestimate the value that theoretical perspectives had on their professional development, and expressed the need to understand the "unknown" emotional side to sports psychology, as Abu went on to explain, "I see Stage 2 as where you develop all 
of the emotional skills needed. Stage 1 is more about underlying content... but I'd love for a Master's course to consider emotional control for the consultant."

Emotional labor as practice. Although participants recalled specific physical facets of emotional performance throughout their development, students were unaware of emotional labor as a phenomenon and found it difficult to convey the necessary service-delivery competencies needed to thrive as a sports psychologist.

Physical emotional performance. While not explicitly referring to the multi-faceted skills involved in enacting emotional labor, participants vocalized the need to understand how one physically conducts themselves during athlete interactions, "maybe just getting to know yourself and your own reactions to a point where you can channel things without necessarily showing it through your body and face" (Gracie). Franklin also noted verbal and non-verbal communication skills such as articulating complex concepts, vocal intonation, and body language were considered important competencies, "I'd probably consider my body language, the way I was going to speak, how open [the athlete] would want to be."

Some participants with previous work experience outside sports psychology or academia were more aware of the need to enact emotional labor when working with clients. For example, Franklin worked part time as a recruitment consultant and spoke at length the need to be aware of your own emotions and performance, "There are certainly elements that do cross over well... Being able to fire fight and to keep calm and cool on the outside, even if inside you're going absolutely ballistic and the alarms are going." Nevertheless, it was this non-academic experience that participants felt to be instrumental in their awareness of emotional demands in the workplace.

Need for actionable knowledge. Despite great theoretical knowledge, participants without prior work experience with athletes revealed a knowledge deficit regarding actionable skills and competencies needed when interacting with athletes. Participants 
discussed at length the lack of practical, simulated content in university courses, and how their current educational experiences might fall short of portraying the entire picture of sports psychology practice, “you don’t really know how to react or respond and what to do in many situations. There's probably a range of things that could be really challenging that I can only imagine as opposed to having faced myself." (Gracie). Participants cited several opportunities to integrate the socio-emotional skills involved in enacting emotional labor into coursework and examination requirements of the Stage 1 postgraduate course. For example, Tom explained, "we need more role playing where we put ourselves in the shoes of a consultant and someone else plays the athlete, or people playing a team and you're doing a workshop." There was a general consensus among participants regarding effective teaching delivery and examination of emotional labor:

Don't just tell us, get us to do it! I know people who are on the fence about starting Stage 2, but they have no way of knowing. It's really important to get some kind of experience during Stage $1 \ldots$ I am literally going into Stage 2 with no idea what it is to be a sports psychologist or how to do it. (Toyah)

There was some discrepancy among the participants in terms of the legality to gain experience in Stage 1. Despite ethical concerns, Gracie undertook a supervised experience placement at local sports club using a "coach" label, as opposed to the legally-protected SEP label, and said that experience alone was more valuable than textbook based learning during their studies:

When you're new to sports psychology, the emotional side has been mentioned to you but you don't even think about it. In terms of teaching, it's important to be aware of what the emotional skills are... I was given the opportunity in my Master's to work with some athletes and I felt that that was an amazing opportunity in terms of actually understanding and applying what you're learning. 
Hence, there is a gap between the expectations and awareness of emotional labor at this stage of professional development and a need for experiential learning yet, such opportunities are blurred by legal, competitive, and logistical issues.

\section{Trainee Sport and Exercise Psychologists (Supervised Practice)}

Emotional labor to survive. The enactment of emotional labor encapsulated the everyday tasks and practice of trainees. Specifically, the participants shared stories about attracting and interacting with clients in supervised practice, and how the enactment of emotional labor was used as a survival tool to gain experience and navigate complex emotional transactions.

The sales pitch. The act of "selling" your services as a trainee sports psychologist was imperative to gaining the requisite number of hours experience to complete supervised practice and involved emotional labor strategies to increase chances of success. Dan verbalized the personal struggles associated with attracting clients as a self-employed trainee, through voluntary or paid services, as a means of access into sport organizations:

I think emotions are a massive barrier to achieving your goals. At first I was certainly very risk averse, and I probably could have advanced my training a lot faster and further if I'd taken more risks in terms of just getting myself out there a little bit.

Later, the same participant indicated how the title of "trainee SEP" added a level of difficulty and emotional effort when enacting the "sales pitch" to potential clients, "my experience is that you have to go out and find the work for yourself, which requires a lot of emotion management and your expectations and managing that fear of getting yourself out there and then failing to find any work." In echoing these sentiments, Alice recalled the emotion regulation required when meeting potential clients, "You need to know you're going to feel uncomfortable, doubt yourself... and people are not going to take you seriously as an unpaid trainee." 
Acute awareness of emotional demands. The trainee participants in this study discussed the immediate recognition of the personal and professional emotional demands encountered as a trainee sports psychologist. On gaining further training experiences, Beth reflected on the emotional factors that influence how she interacts with clients, "People tend to come to train the way they feel, rather than the way they think. I think [acknowledging emotions] is vital, no matter who you see or what issue it is..." Sally-Ann recollected their experiences working in a large sports organization and how it became a priority to understand how their emotional displays influenced delivery:

I'm quite a naturally anxious person... but I wouldn't say many people know that. Over a number of years, especially in a cricket environment, realizing that I'm going to have to find a way to manage things, I found skills and ways of doing that... It's all very well me thinking I know what I'm talking about, but if I can't deliver that with confidence or in a short manner with the athlete, then it doesn't mean a great deal. As a novice in the field, it was imperative to understand what types of behaviors, emotional displays, and attitudes towards particular stakeholders were acceptable in order to foster professional working relationships. Although participants acknowledged the role emotions play in their practice, Elva discussed how understanding emotional labor came with experience:

When you start going out working with clients on a regular basis, for me this was about a year into Stage 2, is when you actually start understanding the actual practicalities of dealing with emotions... You become a little bit more aware of the faculties of individuals that are sitting in front of you.

Participants that were practicing in line with the humanistic view of psychological practice were often engaging in emotional transactions that demanded the feigning of desirable emotions, as illustrated by Alice, “I spend a lot of time acting like I don't really feel 
anything, sympathizing with people but without necessarily engaging in their emotions. I feel like I carry around an awful lot of people's baggage." The incongruence between felt emotions and observable emotional performances by the trainee towards the client poses the case for formal consultant peer groups or social support within the psychology arena, as a method of coping with emotional demands.

Pretending to be a sports psychologist. At the beginning of supervised practice, some participants expressed their lack of preparedness to deliver theoretical content learned in Stage 1 in real life situations with clients, which in turn indicated the education and training gap with regards to emotional labor. Despite an eagerness to perform well, Elva discussed the need to feign desired emotions through observable emotional performances during interactions:

I definitely was ready to give it my best shot but I felt very aware that I didn't know what I was doing. In terms of emotion management, the experience I've had most frequently is trying not to let them see that I'm thinking I've no idea what I'm doing. Similarly, Beth described the unsettling feeling of being an imposter during her initial consultations, "It was like pretending to be a psychologist... I really need to learn and be comfortable with something before I can apply it. I felt like a fraud because I didn't know how to be a professional." Despite the knowledge base gained from prior studies, participants struggled to enact and apply the psychological principles learned to the clients in front of them. Such experiences were effortful and reflected the gap in educational provision with regards to practically delivering sports psychology services. For example, Dan recalled the instantaneous change in their composure when presenting in front of large groups of athletes:

The best way I can describe it, to use an acting analogy, is literally just to keep calm and carry on. Literally up until the second before my first word, I was feeling nervous. Then straight away it was like, "Bang! Okay, I'm into it. I'm not being 
nervous anymore, I have to be confident because that's the only way I'm going to communicate anything to anyone."

For participants who were more experienced as trainees, there was a sense of increased self-efficacy to express more authentic emotions during their practice:

"It's important to not to copy someone else, don't change your personality or try too hard. Somebody's contacted you because they like what they've heard or seen, so don't differ from that, it's more having that belief in yourself. I think subconsciously there's still things I'm working on, it's not like I feel like I know it all, at all.” (Elva)

Emotional labor as a professional development tool. This theme details how the enactment of emotional labor could be further enhanced as a professional skills requirement in supervised practice.

Desired prior experience. Participants expressed the difficulties of transitioning from classroom-based work to supervised practice. Some participants felt there was a lack of formal, explicit educational groundwork in Stage 1 related to the emotional realities of sports psychology consultancy that had a lasting influence on their learning throughout supervised practice. When asked about the transition to supervised experience, Elva shared a somewhat nervous response from their master's degree about heading into uncharted territory with clients,

There was a few of us who wanted to go to Stage 2 and somebody had asked, "Well, how does psychology actually work?" and the lecturer said, "Well, just what we've been talking about." It seemed too simple. "Well, this can't be it... Are we really equipped to be working with people?" It felt like we only read out of textbooks... Despite the theoretical knowledge gained at Master's level, the potential lack of experience conversing with potential recipients of psychological services affected their initial consultancies in supervised practice. The initial consultancies with athletes were often 
uncomfortable experiences, and many participants recalled the need to act like they were somebody else,

I remember my first time like it was yesterday. I had to deliver two different workshops to three different groups, so I couldn't be standing in front of them being remotely anxious, or show any signs of it... We were talking about body language and I stood at the front of the group and I'm slouched, looking at the floor, talking quietly, and I asked "Do you think I'm a confident person?" and they were all like "No.” In my head I'm thinking, "Well, that's hilarious because I'm not actually confident. I must be kidding myself!"' (Dan)

Participants were eager to share their recommendations to bridge the emotional labor skills gap between Stage 1 and Stage 2. For example, Elva would have liked to understand how practitioners deal with their felt and expressed emotions during consultations, through confessional tales, guest lectures or shadowing, "Having somebody experienced talk about how they deal with emotions in real time and in real life, and whatever theories we've been using, how they've been applied in practice." The discrepancy between the content taught at Master's level and the applied settings in supervised practice left participants feeling underequipped with emotional labor strategies needed when negotiating professional relationships. Beth said, "If I learned more practical stuff I think it would be useful because emotions are real life. Even a small module where it focuses on emotions and you as a psychologist, how you are going to deal with things."

Trainee development opportunities. Throughout the interviews, participants emphasized the need to advance and formalize personal and skills-based competency development opportunities that better reflect the emotional labor required in daily practice. When discussing the gaps in knowledge that could be improved during supervised practice, Sally-Ann reflected on the balancing act of negotiating emotional transactions with clients, 
"We need to understand the transition from the "psych skill stuff" into how you start to open up more difficult conversations. I think something around recognizing when as a trainee you're ready to go that next step of conversation."

Given the myriad emotion-laden conservations trainees might experience during supervised practice, additional guidance on the implications of client disclosure and methods of coping would benefit trainees on a personal and professional level. Despite encountering such challenges, some participants asserted that the best method of learning about the realities of emotional labor was "to do", as opposed to classroom-based teaching methods. Sky added "Let's say you've been in a challenging situation and you make a mistake or you panic and lose your nerve in front of the athlete. It's all about you learning from those mistakes... You can't read that in a book." Also, participants voiced mixed opinions with regards to reflecting on such practical experiences as a compulsory area of professional development. When asked about the reflective process, some participants had not considered emotional labor within their accounts, as Elva summed:

I'm not sure that I ever have particularly reflected on emotion management per se. Self-management? Yes, probably... I've reflected on things like stuff I do and don't discuss with people... It's more management of actually how I behave and what I say probably more than how I handle my emotions.

From a personal perspective, participants discussed the independent nature of the supervised practice qualification, despite supervisory and central administrative support, and how this feeling was inherent throughout their professional development. This was summarized by Beth who felt the financial and logistical barriers to attending CPD sessions in supervised practice left them feeling isolated and unable to mitigate the emotional burdens of practice: 
We need clearer opportunities where trainees develop certain skills that are expected throughout that Stage 2 rather than me and my supervisor trying to work out how we're going to gain that experience. Can there be a series of three or four workshops that you're expected to go along to which opens up that network of trainees?

\section{Neophyte Sport and Exercise Psychologists}

Emotional labor as a "new" professional. The enactment of emotional labor (i.e., surface acting, deep acting, and authentic emotional expression) was described by the participants as a vital service-delivery competency that was implicit in their development.

Enhanced self-awareness. When discussing levels of preparedness for enacting emotional labor as a qualified practitioner, Joe explained the transferable skills gained through direct experience with athletes and the application of their own philosophy:

From a knowledge base, I think [the master's course] prepared me very well. From a practical, experienced base, I felt there were more skills that I needed or probably picked up during my supervised practice... I learnt a lot of transferable skills within that window that then meant that the psychology side became a little bit more natural and easier to deliver.

Participants discussed how their levels of self-awareness typically grew sometime after gaining chartered status, thus increasing the importance of reflecting on emotional labor. I think having that confidence then in that gave me the ability to manage and be honest with my emotions. There's this eagerness to just get through Stage 2 and work with as many people as possible and work within the many different experiences as possible that our own emotions get neglected. We don't want to face that. We're knackered and we might be moving towards burnout, or we're not actually working that effectively with someone because we don't really understand our philosophy 
enough and we get stuck in that kind of spiral of, like, is it about me or is it actually about my client? And I think that confuses that emotional management. (Tina) As reflected on by Tina, self-realization issues in relation to practitioner philosophy and identity influenced their ability to create meaningful working alliances with clients as a trainee, but the award of practitioner psychologist status increased their confidence and congruence with their own emotions. Nevertheless, enhanced self-awareness posed issues related to emotional labor, and amplified what Joe did not yet know:

I think you also become quite aware of what you don't know. There are quite a few books around the confidence crisis that the newly qualified practitioner or, imposter syndrome that a lot of $\mathrm{PhD}$ students go through towards the latter stages of their research.

Emotional labor as self-care. On becoming qualified psychologists, participants recognized the transient and long term difficulties associated with enacting emotional labor, and urged for more consistent supervisory and training support for neophyte practitioners.

Support mechanisms. Discussing the transition to becoming a qualified practitioner, participants in this study did not feel it was appropriate to give up supervision, "It's not necessarily a prerequisite to carry on with supervision once we're qualified, and I think that tends to be something the BPS could definitely look at because I think ongoing supervision is vital" (Tina). The same participant went onto state their reasons for wanting to continue supervision,

I won't necessarily feel at the end of the session that I've understood what the conversation has been about, but I do know that I am a bit of a sponge without realizing it, so I do soak up my clients' emotions, and they affect mine. I have to manage that very carefully because otherwise I burn out and my life becomes their lives and I get all consumed by it. (Tina) 
At this stage in their career, this participant was overtly aware of the sometimes debilitating effects and needed one-to-one peer support as a form of coping. Another participant discussed the need to obtain personal counselling to deal with the fallout of emotional labor, "I go to my own counsellor as well, because I believe that in order to be in the sort of counselling consultant sport psych you need to know what it's like to be on the other side of the room as well" (Sammy).

Emotional competency training. Due to the independent nature of Stage 2, the participants felt that supervised practice did not provide an explicit overview of the interpersonal and coping skills needed to function in light of emotional labor requirements. Indeed, this led to issues with aligning to their preferred philosophical approach to psychology:

In the nicest possible way, just completing Stage 2 doesn't necessarily make you a brilliant practitioner and it takes time to step back from the challenges. I wouldn't say that [supervised practice] gave me the blueprint to say, "This is how you do emotion management," but it encouraged me to create the blueprint to get it done. (Joe) One participant argued that the emotional labor of practice should be explicitly covered throughout education and training, and if this was the case they would have arrived at the realization much quicker than through trial and error:

I think emotional competency sits as an implicit outcome of the training through Stage 1 and Stage 2. You could easily argue that it should be in its own competency in its own right, but it would be slightly difficult to demonstrate as it hasn't got a paper-based format as opposed to the current reflective practice elements of qualification pathway. But I think to be a little bit more explicitly indicated as to this why you're learning those situations, just so when the situations do arrive in practice, you're able to recognize them a little bit faster. (Charles) 
Another participant echoed this sentiment, and encouraged university institutions and professional associations that deliver CPD to engage with the complexities of sports psychology:

You're working with a 17-year-old shot-putter, they've arrived ten minutes late to your session because they got stuck in the car on the way over between college and university, little things like that makes that situation seem a bit more human, which then you might be thinking straight away from an emotional management perspective, "If this person's running 15 minutes late, how are they going to appear to you initially?" They may be flustered, they might be sweating, and then does that influence the way you then extract or your awareness of certain things? (Sky)

\section{Experienced Sport and Exercise Psychologists}

Emotional labor as a professional resource. Practitioners in this group enacted emotional labor to develop professional relationships, to cope with emotion-laden transactions, and were more likely to portray authentic emotions.

Necessity to enact emotional labor. Many participants reported that the enactment of emotional labor was necessary to navigate complex emotional transactions. This heightened level of awareness and preparedness to enact emotional labor in a variety of situations was shared by Jake, "[Emotional labor] is extremely important as well as understanding how we can regulate people's emotions and their mistakes and how that aligns to the sporting perspective and also non-sporting as well." The necessity to form professional relationships was not overstated by the participants, and a useful resource to help foster those relationships was an increased awareness of and competence in enacting emotional labor. For example, Stefan stated, "The basis of a human relationship in sports psychology is about trust, rapport, respect, engagement... Managing yourself within a relationship, being clear of what your needs are within a relationship helps you operate more effectively." This view was reinforced 
by Amy, who commented that there is a fine balance between self and social emotional awareness that needs to be considered when practicing, "You have to be able to understand your emotions and understand how they are coming across, and understand the impact they are having on you and your client and your practice."

Terry had worked alongside clinical psychologists throughout his career, and discussed the need to cater to the complexities of clients to successfully deliver their service: There's lots of insecurities in humans. There's lots of things going on for people and just judging that and dismissing it isn't a particularly effective way or working so if you're a good psychologist you're automatically going to function and operate better.

Authenticity. Some participants reported that displays of authentic emotions increased as they became more experienced practitioners. This perspective was endorsed by Amy, and was fueled by a holistic awareness of the emotional demands of sports psychology, based on previous experiences, especially in relation to personal self-awareness:

The thing is about life and being a practitioner is that you have to be yourself. You can't go through life being someone that you're not, and that's the same as being a sport psychologist... There has to be some kind of acceptance there otherwise you're going to be pretty crap at what you do. And it could be that your emotions, your natural emotional reactions are absolutely congruent to the work, and so you don't have to do anything, just sit back and enjoy the ride.

As the participants became more comfortable with their professional selves, and negotiated their own professional boundaries, this led to development of productive relationships with clients. Stefan remarked that psychologists need to be comfortable with bringing their own emotions to validate and strengthen relationships with athletes, "Relationships mean managing emotions between people. Managing is sometimes quite difficult with emotions and that as a psychologist you bring emotions, you bring your own 
emotions and outlook to any professional relationship." The notion of being authentic towards athletes was ultimately rewarding, though this did not override the need to enact emotional labor in other challenging situations.

Emotional labor as lifelong learning. Throughout the analysis, it was evident that there were many undeveloped but potentially useful learning opportunities to reflect on emotional labor. Participants outlined how the enactment of emotional labor was often omitted in relation to supervision, reflective practice, and classroom-based learning events (i.e., CPD), and does not sufficiently reflect the daily practice of practitioner psychologists.

Ongoing supervision. Participants suggested that regular supervision after qualifying played a significant role in their understanding of emotional labor, despite formal supervision not being a compulsory measure. For example, Stefan shared their approach to supervision as an opportunity to reflect upon their own mental health needs, "When you qualify, get ongoing supervision... The real personal challenges are not necessarily about, "This intervention is not working with such and such", but it is more about how you are operating within yourself." Stefan, who has been involved in sports psychology for over two decades, spoke of the long term effects that emotional labor can have on your mental health, and highlighted the stigma of psychologists gaining emotional support:

Some of the difficulties [psychologists] have is because they are psychologists.

Psychologists should never have any problems and should be able to work everything out. If we want to manage our emotions well, we need to share how we feel... Just like Doctors are not immune to getting cancer just because they know about it, it does not mean we are immune to illness.

Indeed, in neighboring accredited psychology disciplines, supervision is a compulsory requirement. Terry stated his disdain for how some practitioners approach supervision after becoming accredited psychologists: 
Without overstating it, we have failed in how we should produce and train sport psychologists. I do think [the BPS] can do more, and that starts with the quality and frequency of supervision. You can comfortably get away with seeing somebody once every three months, whereas in clinical psych you have to see someone every week and a half.

Reflective practice. When discussing the ongoing duties of qualified SEPs, participants were more likely to regularly and formally reflect on their emotional labor. The value of reflective practice was demonstrated by Jake:

Through reflective practice it's likely that you'll see when you are having an emotional reaction to certain things and that you may be portraying emotions that you shouldn't... Isolate the incidents and the situations and the triggers, emotions that are creating a problem, and then regulate in a way that's appropriate to you. (Jake) Participants also highlighted how one's personal qualities and philosophies were integral to adapting to sports environments, and asking specific questions related to emotional labor was critical to growth as a psychologist:

What is your belief system? What is your approach to life? How does that fit with this environment? It is working through all of those things and then knowing what are your strategies to manage that? How do you get control over your emotions? How do you get control over your behaviors and your thought processes? It is taking the same approach to yourself that you would to anybody else who you work with. (Charlotte) Nevertheless, some participants expressed that reflective practice as a teaching method was lacking in effectiveness, and a more applied stance should be taken when teaching students how to reflect. For instance, Jake suggested scenario-based learning, either in hypothetical or real-life contexts, should be the driving force behind reflective practice: 
I'm about to go and experience this, what are likely going to be the challenges? How are you going to face them? Both at an individual level and as a collective. There should be some type of review about how did I function? How did I deal with my emotions after the event but in light of what you said was going to be a challenge? In the same way we'd expect athletes to preview and review, support staff should preview and review around their emotions that they felt. (Jake)

The act of reflecting on the social, performative aspects of professional practice, including emotion regulation and emotional expressiveness, might glean enhanced awareness and preparedness for emotional labor in future situations.

\section{Discussion}

The aim of this manuscript was to explore the emotional educational-training-practice gap in the professional formation of SEPs. By virtue of this objective, participants were invited to share their experiences in relation to the theoretical, practical, and selfadministered emotional content that has influenced their professional development. Accordingly, we invite the certification associations, regulatory bodies and education providers (i.e., universities) to reflect on a list of applied recommendations designed to reduce the apparent emotional labor skills deficit throughout the professional formation of sports psychologists (see Table 3).

Themes developed from the Stage 1 participant group indicated an implicit understanding of the physical facets of emotional labor (i.e., emotional performance) and were aware of the influence of verbal and non-verbal communication through specific taught modules within master's courses. Nevertheless, such knowledge in the context of enacting emotional labor in simulated situations was absent. When considered alongside findings in counselling and psychotherapy (Skovholt \& Rønnestad, 2011), advanced students are expected to "look, act, think, feel and perform at a basic established professional level" (p. 
63). Hence, sport and exercise psychology students are currently experiencing an interpersonal/practical skills shortage with regards to emotional labor (cf. Harwood, 2016). Unlike educational approaches in counselling psychology whereby students can volunteer their time with clients or shadow counsellors, the present results showed that the participants were often deprived of this opportunity due to legal and ethical limitations.

For the participants at supervised practice, the feeling of "pretending" to be a psychologist was underlined by the need to surface act (i.e., feign desired emotions; Grandey \& Melloy, 2017). Apart from those who had previous work experience, not necessarily within the sports psychology sphere, the process of navigating initial consultations with athletes was often alien, and led to the enactment of emotional labor without explicit realization. The idea of "fake it until you make it" (Humphrey, Ashforth, \& Diefendorff, 2015 , p. 775) is resonant here, as previous research has demonstrated the potentially detrimental personal (e.g., mental health issues; Hings et al., 2018) and professional (e.g., emotional exhaustion and burnout; Grandey et al., 2015, see also Larner et al., 2017) outcomes of such professional acting. From the outset, to preserve and maintain trainee welfare, structured training sessions that focus on sharing experiences regarding emotional labor should be advocated. Given the highly competitive nature of acquiring sports psychology supervised experience, trainees should be aware of and better prepared for the emotional labor required to create a professional first impression, through enhanced theoretical and practical understanding from previous studies and supervision (see Table 3).

Building upon experience in supervised practice, newly qualified practitioners in this study reported an enhanced awareness of the role emotional labor might have in client interactions. Although this awareness was beneficial when participating in emotion-laden transactions, participants felt this knowledge would have helped them earlier on in their development. Indeed, neophytes in this study intrinsically participated in the reflective 
practice process to learn from their supervised experiences (Cropley et al., 2010). Also, neophytes warned against a lack of mandatory supervision or peer-mentoring following qualification, which left practitioner feeling isolated and unable to vent in a professional capacity. Despite achieving qualified psychologist status, ongoing feelings of imposter syndrome and uncertainty in their ability to act professional could have been mitigated through effective reflective practice focused on the emotional practicalities of working as a psychologist (Cropley, Baldock, Mellalieu, Neil, Wagstaff, \& Wadey, 2016).

As participants became more experienced (i.e., experienced and senior professional phase; Skovholt \& Rønnestad, 2011), an alignment between the personal and professional selves, thus the embodiment of their professional philosophy in sports psychology, led to increased authenticity during interactions with already established clients (Poczwardowski, 2017). Findings in the healthcare domain has shown that developing a personal climate of authenticity when interacting with patients led to reduced strain and burnout from emotionladen transactions (Grandey, Foo, Groth, \& Goodwin, 2012). Nevertheless, the participants shared stories about the need to surface and/or deep act, especially when encountering professional challenging situations (Hings et al., 2018), and regularly reflected upon their capabilities in this area as written and spoken word. Indeed, this group was unyielding in their opinions regarding the effectiveness of reflective practice as currently portrayed by the BPS in course materials. This observation lends support to Huntley, Cropley, Gilbourne, Sparkes and Knowles (2014) in their recommendation to adequately develop the "how to" and train reflective practice, with the need to acknowledge more personal aspects of practice (Table 3).

Although the data collected in this study provided a cross-sectional snapshot into the views of prospective and qualified SEPs, the results presented here suggest several courses of action for university educators to facilitate better understanding of emotional labor in 
professional practice. Updated curricula that incorporates theoretical (e.g., trifocal theory of emotional labor), and practical (e.g., role plays with student athletes in active conditions) skills and approaches that encapsulate emotional labor would likely invoke confidence in students beginning supervised practice. Research in other caring professions such as nursing has shown role playing under pressure simulated conditions increased self-efficacy in relation to nursing practice (i.e., interacting with patients) and higher levels of satisfaction with their course (Sinclair \& Ferguson, 2009). Further, institutions could develop links with existing university services (e.g., student sport and recreation societies) to maximize opportunities for master's students to present ideas to athletes. As echoed by the participants, there are ethical and legal matters to consider before working with athletes in any capacity. Nevertheless, presenting sports psychology ideas to athlete groups would allow trainees to experience the enactment of emotional labor in an ethically safe manner. To bridge the gap between Stage 1 and 2 (i.e., advanced students to novice professionals; Skovholt \& Rønnestad, 2011), closer collaborations between institutions, professional societies and regulatory bodies (e.g., BPS) in the form of workshops, visiting lectures, and open days might reduce the anxiety related to transitioning between Master's level education and supervised practice (Table 3).

In terms of the implications for professional societies and regulatory bodies, a key priority is to explicitly align existing codes of practice to represent the pervasiveness and potential consequences of emotional labor. To elaborate, the most recent code of practice details the importance of establishing appropriate, emotionally distant and trustworthy professional relationships with clients. The interpersonal skills required to deliver such professional competencies, as detailed by experienced SEPs in this manuscript, confirm the need to adequately train and prepare practitioners for the emotional labor required as part of their daily activities. Further, there are opportunities for the BPS to develop CPD provision in relation to practitioner emotional labor. Although supervision is not compulsory for qualified 
practitioners, a mechanism enabling access to ongoing peer support that emphasizes practical advice on how to deal with the emotional demands of practice could be developed.

Several questions warrant further investigation in light of the results of this study. The addition of theoretical and practical content related to emotional labor into university curricula provides the opportunity to longitudinally evaluate the value added to master's level education and the transition to supervised practice. Indeed, auto/ethnographic reflective accounts of Stage 1 students enacting emotional labor in supervised presentation with clients would provide original insight into navigating complex sports environments (i.e., emotional display requirements). As noted previously, the personal and professional effects of emotional labor whilst at work can have negative connotations for well-being (e.g., emotional exhaustion, disillusionment, and burnout). Indeed, research examining the prevalence and pervasiveness of emotional labor and associated outcomes across the profession would benefit this line of inquiry. Future research should consider the spillover effects of daily enactment of emotional labor strategies on practitioners outside of the work sphere (i.e., at home), and how this might influence service delivery.

To conclude, there is an emotional labor skills gap in the education and training of SEPs. Emotional labor is relatively implicit knowledge in the professional development of SEPs despite the emotional demands that are pervasive in practice. It is pertinent that the transition period between education (i.e., Stage 1) and supervised practice (i.e., Stage 2) becomes more fluid through theoretical and practical awareness of the emotional realities of working with clients in sport. Moreover, mutually beneficial support mechanisms for neophyte and experienced psychologists including mandated one-to-one or group (e)supervision and/or experience sharing sessions may mitigate the negative consequences associated with surface acting and inauthentic emotional expression. 


\section{References}

Braun, V., Clarke, V., \& Weate, P. (2016). Using thematic analysis in sport and exercise research. In B. Smith \& A. C. Sparkes (Eds.), Routledge handbook of qualitative research in sport and exercise (pp. 191-205). UK: Routledge.

Burke, S. (2016). Rethinking 'validity' and 'trustworthiness' in qualitative inquiry: How we might judge the quality of qualitative research in sport and exercise sciences? In B. Smith \& A. C. Sparkes (Eds.), Routledge handbook of qualitative research in sport and exercise (pp. 330-339). UK: Routledge.

Cropley, B., Baldock, L., Mellalieu, S. D., Neil, R., Wagstaff, C. R. D., \& Wadey, R. (2016). Coping with the demands of professional practice: Sport psychology consultants' perspectives. The Sport Psychologist, 30(3), 290-302. doi: 10.1123/tsp.2015-0125

Cropley, B., Hanton, S., Miles, A., \& Niven, A. (2010). Exploring the relationship between effective and reflective practice in applied sport psychology. The Sport Psychologist, 24, 521-541. doi: 10.1123/tsp.24.4.521

Fletcher, D., \& Maher, J. (2013). Toward a competency-based understanding of the training and development of applied sport psychologists. Sport, Exercise, \& Performance Psychology, 2(4), 265-280. doi: 10.1037/a0031976

Grandey, A., Foo, S. C., Groth, M., \& Goodwin, R. E. (2012). Free to be you and me: A climate of authenticity alleviates burnout from emotional labor. Journal of Occupational Health Psychology, 17(1), 1-14. doi: 10.1037/a0025102

Grandey, A. A., \& Gabriel, A. S. (2015). Emotional labor at a crossroads: Where do we go from here? Annual Review of Organizational Psychology \& Organizational Behavior, 2, 323-349. doi: 10.1146/annurev-orgpsych-032414-111400 
Grandey, A. A., \& Melloy, R. C. (2017). The state of the heart: Emotional labor as emotion regulation reviewed and revised. Journal of Occupational Health Psychology, 22(3), 407-422. doi: 10.1037/ocp0000067

Grandey, A. A., Rupp, D., \& Brice, W. N. (2015). Emotional labor threatens decent work: A proposal to eradicate emotional display rules. Journal of Organizational Behavior, 36(6), 770-785. doi: 10.1002/job.2020

Hanna, P. (2012). Using internet technologies (such as Skype) as a research medium: a research note. Qualitative Research, 12(2), 239- 242. doi: $10.1177 / 1468794111426607$

Harwood, C. (2016). Doing sport psychology? Critical reflections of a scientist-practitioner. In M. Raab, P. Wylleman, R. Seiler, A. Elbe, \& A. Hatzigeorgiadis (Eds.), Sport and exercise psychology research: From theory to practice (pp. 229-250). London, UK: Elsevier Inc.

Health Care and Professions Council. (2018). Protected titles. Retrieved from http://www.hcpc-uk.co.uk/aboutregistration/protectedtitles/

Hings, R. F., Wagstaff, C. R. D., Anderson, V., Gilmore, S., \& Thelwell, R. C. (2018). Professional challenges in elite sports medicine and science: Composite vignettes of practitioner emotional labor. Psychology of Sport \& Exercise, 35, 66-73. doi: 10.1016/j.psychsport.2017.11.007

Hings, R. F., Wagstaff, C. R. D., Thelwell, R. C., Gilmore, S., \& Anderson, V. (2018). Emotional labor and professional practice in sports medicine and science practitioners. Scandinavian Journal of Medicine \& Science in Sports. 28(2), 704-716. doi: $10.1111 /$ sms.12941

Humphrey, R. H., Ashforth, B. E., \& Diefendorff, J. M. (2015). The bright side of emotional labor. Journal of Organizational Behavior, 36(6), 749-769. doi: 10.1002/job.2019 
Huntley, E., Cropley, B., Gilbourne, D., Sparkes, A., \& Knowles, Z. (2014). Reflecting back and forwards: An evaluation of peer-reviewed reflective practice research in sport. Reflective Practice, 15(6), 863-876. doi: 10.1080/14623943.2014.969695

Lindsay, P., Breckon, J. D., Thomas, O., \& Maynard, I. W. (2007). In pursuit of congruence: Are practitioners' personal philosophies aligned with their 'chosen' method of service? The Sport Psychologist, 21(3), 335-352.

McEwan, H. E., \& Tod, D. (2014). Learning experiences contributing to service-delivery competence in applied psychologists: Lessons for sports psychologists. Journal of Applied Sport Psychology, 27(1), 79-93. doi: 10.1080/10413200.2014.952460

Owton, H., Bond, K., \& Tod, D. (2014). "It's my dream to work with Olympic athletes": Neophyte sport psychologists' expectations and initial experiences regarding service delivery. Journal of Applied Sport Psychology, 26(3), 241-255. doi: $10.1080 / 10413200.2013 .847509$

Poczwardowski, A. (2017). Deconstructing sport and performance psychology consultant: Expert, person, performer, and self-regulator. International Journal of Sport and Exercise Psychology. doi: 10.1080/1612197X.2017.1390484

Skovholt, T. M., \& Rønnestad, M. H. (2011). The long textured path from novice to senior practitioner. In T. M. Skovholt, \& M. Trotter-Mathison (Eds.), The resilient practitioner: Burnout prevention and self-care strategies for counselors, therapists, teachers, and health professionals ( $2^{\text {nd }}$ ed). (pp. 39-77). New York, USA: Taylor \& Francis.

Smith, B. (2018). Generalizability in qualitative research: Misunderstandings, opportunities and recommendations for the sport and exercise sciences. Qualitative Research in Sport, Exercise \& Health, 10(1), 137-149. doi: 10.1080/2159676x.2017.1393221 
Smith, B., \& McGannon, K. (2017). Developing rigor in qualitative research: problems and opportunities within sport and exercise psychology. International Review of Sport \& Exercise Psychology, 1-21. doi: 10.1080/1750984X.2017.1317357

Smith, B., \& Sparkes, A. C. (2016). Introduction: An invitation to qualitative research. In B. Smith, \& A. Sparkes, (Eds.), Routledge handbook of qualitative research in sport and exercise (pp. 1-7). London: Routledge.

Sparkes, A. C., \& Smith, B. (2014). Qualitative research methods in sport, exercise and health: From process to product. Oxon, UK: Routledge.

Tod, D. (2007). The long and winding road: Professional development in sport psychology. The Sport Psychologist, 21(1), 94-108. doi: 10.1123/tsp.21.1.94

Tod, D., \& Bond, K. (2010). A longitudinal examination of a British neophyte sports psychologist's development. The Sport Psychologist, 24(1), 35-51. 10.1123/tsp.24.1.35

Tod, D., Marchant, D., \& Andersen, M. B. (2007). Learning experiences contributing to service-delivery competence. The Sport Psychologist, 21(3), 317-334.

Vaismoradi, M., Turunen, H., \& Bondas, T. (2013). Content analysis and thematic analysis: Implications for conducting a qualitative descriptive study. Nursing \& Health Sciences, 15(3), 398-405. doi: 10.1111/nhs.12048

Wagstaff, C. R. D., Fletcher, D., \& Hanton, S. (2012). Exploring emotion abilities and regulation strategies in sport organizations. Sport, Exercise, \& Performance Psychology, 1(4), 268-282. doi: 10.1037/a0028814

Woolway, T., \& Harwood, C. G. (2018). Consultant characteristics in sport psychology service provision: A critical review and future research directions. International Journal of Sport \& Exercise Psychology. doi: 10.1080/1612197X.2018.1462230 


\section{Tables and Figures}

Table 1. Participant inclusion and exclusion criteria.

\begin{tabular}{|c|c|c|}
\hline & Inclusion criteria & Exclusion criteria \\
\hline $\begin{array}{l}\text { Experienced sport and } \\
\text { exercise psychologists }\end{array}$ & $\begin{array}{l}\text { Qualified and accredited sport } \\
\text { and exercise psychologists } \\
\text { including BPS accreditation and } \\
\text { HCPC accreditation, and in part } \\
\text { time or full-time consultancy } \\
\text { work at the time of study. }\end{array}$ & $\begin{array}{l}\text { Unqualified and unaccredited } \\
\text { sport and exercise psychologists, } \\
\text { practitioners holding British } \\
\text { Association of Sport and Exercise } \\
\text { Science accreditation with a } \\
\text { specialization in sports } \\
\text { psychology only. Those not in } \\
\text { part time or full-time consultancy } \\
\text { work at the time of the study. }\end{array}$ \\
\hline $\begin{array}{l}\text { Neophyte sport and exercise } \\
\text { psychologists }\end{array}$ & $\begin{array}{l}\text { Qualified and accredited sport } \\
\text { and exercise psychologists } \\
\text { including BPS accreditation and } \\
\text { HCPC accreditation with less } \\
\text { than two years' experience, and } \\
\text { in part time or full-time } \\
\text { consultancy work at the time of } \\
\text { study. }\end{array}$ & $\begin{array}{l}\text { Unqualified and unaccredited } \\
\text { sport and exercise psychologists, } \\
\text { practitioners holding British } \\
\text { Association of Sport and Exercise } \\
\text { Science accreditation with a } \\
\text { specialization in sports } \\
\text { psychology only. Those not in } \\
\text { part time or full-time consultancy } \\
\text { work at the time of the study. }\end{array}$ \\
\hline $\begin{array}{l}\text { Trainee sport and exercise } \\
\text { psychologists }\end{array}$ & $\begin{array}{l}\text { Trainee sport and exercise } \\
\text { psychologists currently enrolled } \\
\text { on a Stage } 2 \text { BPS accredited } \\
\text { supervised experience education } \\
\text { pathway. }\end{array}$ & $\begin{array}{l}\text { Those not currently enrolled on a } \\
\text { Stage } 2 \text { BPS accredited } \\
\text { supervised experience education } \\
\text { pathway, including BASES } \\
\text { supervised experience. }\end{array}$ \\
\hline $\begin{array}{l}\text { Student sport and exercise } \\
\text { psychologists }\end{array}$ & $\begin{array}{l}\text { Master's students currently } \\
\text { enrolled on a BPS accredited } \\
\text { MSc in sport and exercise } \\
\text { psychology (Stage } 1 \text { of the BPS } \\
\text { accredited education pathway) at } \\
\text { the time of the study. }\end{array}$ & $\begin{array}{l}\text { Master's students enrolled onto a } \\
\text { non-BPS accredited MSc in sport } \\
\text { and exercise psychology (e.g., } \\
\text { BASES accredited or non- } \\
\text { accredited courses). }\end{array}$ \\
\hline
\end{tabular}


Table 2. Participant demographic information.

\begin{tabular}{|c|c|c|c|}
\hline $\begin{array}{l}\text { Participants } \\
\text { (Pseudonym) }\end{array}$ & Gender & $\begin{array}{l}\text { Stage in Professional } \\
\text { Formation* }\end{array}$ & $\begin{array}{l}\text { Qualifications/ } \\
\text { Accreditation }\end{array}$ \\
\hline Toyah & Female & MSc student & $\mathrm{BSc}$ \\
\hline $\mathrm{Abu}$ & Male & MSc student & $\mathrm{BSc}$ \\
\hline Gracie & Female & MSc student & $\mathrm{BSc}$ \\
\hline Tom & Male & MSc student & $\mathrm{BSc}$ \\
\hline Franklin & Male & MSc student & $\mathrm{BSc}$ \\
\hline Elva & Female & $\begin{array}{c}\text { Trainee sport and exercise } \\
\text { psychologist }\end{array}$ & $\mathrm{BSc}, \mathrm{MSc}$ \\
\hline Dan & Male & $\begin{array}{c}\text { Trainee sport and exercise } \\
\text { psychologist }\end{array}$ & $\mathrm{BSc}, \mathrm{MSc}$ \\
\hline Beth & Female & $\begin{array}{c}\text { Trainee sport and exercise } \\
\text { psychologist }\end{array}$ & $\mathrm{BSc}, \mathrm{MSc}$ \\
\hline Alice & Female & $\begin{array}{c}\text { Trainee sport and exercise } \\
\text { psychologist }\end{array}$ & $\mathrm{BSc}, \mathrm{MSc}$ \\
\hline Sally-Ann & Female & $\begin{array}{c}\text { Trainee sport and exercise } \\
\text { psychologist }\end{array}$ & $\mathrm{BSc}, \mathrm{MSc}$ \\
\hline Tina & Female & $\begin{array}{l}\text { Neophyte sport and exercise } \\
\text { psychologist }\end{array}$ & BSc, MSc/CPsychol, HCPC \\
\hline Joe & Male & $\begin{array}{l}\text { Neophyte sport and exercise } \\
\text { psychologist }\end{array}$ & BSc, MSc/CPsychol, HCPC \\
\hline Sammy & Female & $\begin{array}{l}\text { Neophyte sport and exercise } \\
\text { psychologist }\end{array}$ & BSc, MSc/CPsychol, HCPC \\
\hline Charles & Male & $\begin{array}{l}\text { Neophyte sport and exercise } \\
\text { psychologist }\end{array}$ & BSc, MSc/CPsychol, HCPC \\
\hline Sky & Female & $\begin{array}{l}\text { Neophyte sport and exercise } \\
\text { psychologist }\end{array}$ & BSc, MSc/CPsychol, HCPC \\
\hline Stefan & Male & $\begin{array}{l}\text { Experienced sport and } \\
\text { exercise psychologist }\end{array}$ & $\begin{array}{c}\mathrm{BSc}, \mathrm{MSc}, \mathrm{PhD} / \mathrm{CPsychol}, \\
\text { HCPC }\end{array}$ \\
\hline Jake & Male & $\begin{array}{l}\text { Experienced sport and } \\
\text { exercise psychologist }\end{array}$ & BSc, MSc/CPsychol, HCPC \\
\hline Charlotte & Female & $\begin{array}{l}\text { Experienced sport and } \\
\text { exercise psychologist }\end{array}$ & $\begin{array}{c}\mathrm{BSc}, \mathrm{MSc}, \mathrm{PhD} / \mathrm{CPsychol}, \\
\mathrm{HCPC}\end{array}$ \\
\hline Amy & Female & $\begin{array}{l}\text { Experienced sport and } \\
\text { exercise psychologist }\end{array}$ & $\begin{array}{c}\mathrm{BSc}, \mathrm{MSc}, \mathrm{PhD} / \mathrm{CPsychol}, \\
\text { HCPC }\end{array}$ \\
\hline Terry & Male & $\begin{array}{l}\text { Experienced sport and } \\
\text { exercise psychologist }\end{array}$ & $\begin{array}{c}\mathrm{BSc}, \mathrm{MSc}, \mathrm{PhD} / \mathrm{CPsychol}, \\
\text { HCPC }\end{array}$ \\
\hline \multicolumn{4}{|c|}{ Note: BSc: Bachelor of Science degree; MSc: Master of Science degree; PhD: Doctor of Philosophy; } \\
\hline
\end{tabular}


Table 3. A synthesized list of applied recommendations to address the emotional educational-training-practice gap in sport and exercise psychology.

\begin{tabular}{|c|c|}
\hline Phase & Recommendations \\
\hline $\begin{array}{l}\text { Education (i.e., MSc } \\
\text { students) }\end{array}$ & $\begin{array}{l}\text { - Incorporate contemporary theoretical content pertaining to } \\
\text { emotional labor into the curriculum at all stages in the BPS } \\
\text { professional framework for SEPs. } \\
\text { - Practice and hone emotion performance skills under ethical } \\
\text { conditions through innovative teaching methods (e.g., } \\
\text { simulation-based learning). } \\
\text { - To develop a line of communication between accredited } \\
\text { educational providers and professional associations to promote } \\
\text { interpersonal skills development. }\end{array}$ \\
\hline $\begin{array}{l}\text { Training (i.e., Stage } \\
2 \text { and/or trainee } \\
\text { sports }\end{array}$ & $\begin{array}{l}\text { - Assess competencies in relation to skills associated with } \\
\text { emotional labor by updating competency frameworks and/or } \\
\text { experiential/reflection requirements. }\end{array}$ \\
\hline psychologists) & $\begin{array}{l}\text { Implement mandatory supervisory and/or peer-mentoring } \\
\text { frameworks throughout the entirety of SEPs professional } \\
\text { formation. } \\
\text { - Specific training alluding to effective reflective practice in } \\
\text { multiple forms (i.e., written, one-to-one, group, or online } \\
\text { reflection). }\end{array}$ \\
\hline $\begin{array}{l}\text { Practice (i.e., } \\
\text { qualified } \\
\text { practitioners) }\end{array}$ & $\begin{array}{l}\text { - Explicitly highlight the pervasiveness, necessity and } \\
\text { implications of emotional labor to practitioners in official BPS } \\
\text { professional practice guidelines including the code of conduct. } \\
\text { - Promote reflective practice in relation to emotional labor } \\
\text { demands. } \\
\text { - Creation of support mechanisms to discuss issues pertaining to } \\
\text { emotional labor, thus increasing the wellbeing of practitioner } \\
\text { psychologists. }\end{array}$ \\
\hline
\end{tabular}


Figure 1. Timeline of the sport and exercise psychology professional formation process of



participants included in this study. 